\title{
Reclamation and Ecological Service Value Evaluation of Coastal Wetlands Using Multispectral Satellite Imagery
}

\author{
Jinfeng Yan ${ }^{1}$. Jiaxue $\mathrm{Du}^{1} \cdot$ Fenzhen $\mathrm{Su}^{2} \cdot$ Shiyi Zhao ${ }^{1}$ Shixun Zhang ${ }^{1} \cdot$ Pengfei Feng ${ }^{1}$
}

Received: 13 July 2021 / Accepted: 21 January 2022 / Published online: 19 February 2022

(c) The Author(s), under exclusive licence to Society of Wetland Scientists 2022

\begin{abstract}
There are special locational value and natural resources in coastal wetlands. Studying their changes and evaluating their ecosystem service value (ESV) is beneficial for protecting the ecology of coastal wetlands and for maintaining sustainable human development. In this paper, the coastal wetland of Jiaozhou Bay is selected as the research area, an object-oriented method is used to extract shoreline and wetland information, and the coastal wetland reclamation process in Jiaozhou Bay is evaluated. The value equivalent method and market value method are used to evaluate the service value of wetland ecosystems from the perspective of ecological economics. The results show that the reclamation area of Jiaozhou Bay reached $75.2 \mathrm{~km}^{2}$ in 40 years, with nearly $23 \%$ of the bay area eroding. Reclamation engineering, estuary engineering, policy implementation and urbanization are the main factors affecting the changes in the Jiaozhou Bay wetland, and the main direction of wetland succession is natural wetlands $\rightarrow$ artificial wetlands $\rightarrow$ nonwetlands. Wetland reclamation in Jiaozhou Bay has led to the continuous extension of the coastline to the sea, especially during the 2005-2020 period, and the wetland area has declined in area by $116 \mathrm{~km}^{2}$. The changes in the wetland in the past 40 years have affected the changes in the ESV of Jiaozhou Bay, and there have been different synergistic/trade-off relationships in different periods. This research provides data to support the comprehensive ecological management of coastal areas, which is conducive to maximizing the utilization value of wetlands and promoting wetland protection.
\end{abstract}

Keywords Wetland reclamation $\cdot$ Ecological service value $\cdot$ Coastline $\cdot$ Artificial wetland $\cdot$ Jiaozhou Bay

\section{Introduction}

Coastal wetlands are an important part of the coastal system (Sousa et al. 2020) and are essential for human survival and sustainable development (Costanza et al. 1997). Wetlands can help mitigate environmental pollution, protect the coast from erosion by wind and waves, and provide habitats for offshore organisms (Lindley and Lotz-Sisitka 2019). However, according to statistics, approximately $1 \%$ of coastal wetland resources are lost every year (MEA 2005). Such losses will lead to the continuous destruction of wetland

Jinfeng Yan

yanjf2004@163.com

1 College of Geodesy and Geomatics, Shandong University of Science and Technology, Qingdao, China

2 State Key Laboratory of Resources and Environmental Information System, Institute of Geographic Sciences and Natural Resources Research, Chinese Academy of Sciences, Beijing, China ecological structures and functions and result in a severe loss of the value created by wetland ecosystems (Feingold et al. 2018). The global economy is generally more developed and human settlements are more concentrated in coastal areas than in other areas (Guo and Zhang 2019). Necessary wetland reclamation activities can alleviate the contradiction between humans and land and promote economic development (Mayer-Pinto et al. 2018). However, many human activities, such as land reclamation, dam construction, drainage and water intake, mariculture, salt pan construction, and port and wharf construction, have caused wetland degradation (Hou et al. 2016; Liu et al. 2018).

In the twentieth century, more than half of the wetlands in North America, Europe, Australia, and New Zealand were transformed (MEA 2005; Stedman and Dahl 2008; Creighton et al. 2015). Additionally, coastal wetlands are degrading faster in Asia than in Europe (1.1\% per year) (Davidson 2014). For example, in Japan (Suzuki 2003), South Korea (Son and Wang 2009) and Singapore (Glaser et al. 1991), land space has been established for coastal 
industrial and agricultural development due to urban expansion, and large amounts of coastal land have been reserved for various projects, such as storm surge defense projects. Most wetlands are converted into farmland, construction land and lands with other uses (McAllister et al. 2001). China is rich in wetland resources, but rapid economic and population growth has led to overexploitation, and use has become the main problem China faces (Liu et al. 2018). Since the 1990s, coastal reclamation has been particularly concentrated in cities in fragile delta ecosystems, such as Shanghai at the mouth of the Yangtze River, Ningbo along the southern wing of the Yangtze River Delta, and Tangshan near Bohai Bay (Sengupta et al. 2019). The changes in coastal wetlands have far exceeded the carrying capacity of the land (An et al. 2007). Additionally, species diversity has decreased, and the hydrological regulation and selfpurification capabilities of coastal wetlands have weakened (Ritsch and Dunbar 1993). However, the ecological and environmental costs associated with urbanization are often high (Shan and Li 2020) and underestimated because there is no market price reference.

Ecosystem services refer to the benefits that people obtain from an ecosystem, and quantitative evaluations of ecosystem services from the perspective of monetary value are performed based on ecosystem service value (ESV) assessment (Costanza et al. 1997; Lin et al. 2019; Sun et al. 2017). Corresponding research can be traced back to the 1960s, and qualitative and quantitative evaluation methods, multiple regression functions, and spatial modeling methods have emerged over time (Englund et al. 2017; Ochoa and UrbinaCardona 2017). For example, Costanza et al. used the valueequivalent method to estimate the global total range of ESVs (Costanza et al. 1997), including the total market value and nonmarket value. Additionally, Rudolf et al. reviewed more than 320 publications to create an ecological service value database (De Groot et al. 2012) and express the ESVs of major biological communities, including wetland ecosystems, in the form of currency. However, the conversion of the values did not consider uncertainties such as changes in population, changes in natural scarcity, and the marginal value of climate change; thus, the values obtained in both of these studies are considered to be low-end estimates. If the above research is directly applied to the Chinese ecosystem, there will be deviations from the actual conditions. Xie Gaodi et al. derived a new unit price system for ecosystem service evaluation by administering expert knowledge questionnaires based on the Costanza study (Xie et al. 2008); then, they improved the method by constructing a terrestrial ESV dynamic evaluation method through model calculations and a geographic information spatial analysis method. This approach has been widely accepted by the academic community and can be used to evaluate intangible assets such as the ecological benefits of wetlands (Xie et al. 2015).
Many scholars from different disciplines have conducted research on this topic, mainly focusing on changes in landscape patterns, ecological health assessments, and the impacts of management policies on sustainable ecological development (Wu et al. 2017; Sun et al. 2019; Qin and Zhang 2021). Quantifying the complex changes in wetland processes and the wetland service value can help provide data support for sound wetland protection so that limited funds can be efficiently used to promote the reconstruction and restoration of wetlands (Crossman and Bryan 2009). This article focuses on analyzing the detailed changes in various wetland types along Jiaozhou Bay and the changes in the value of ecological services. First, an object-oriented method combined with the band index method is used to extract coastline information and wetland type information from remote sensing images obtained in 9 periods $(1980 / 1$ 985/1990/1995/2000/2005/2010/2015/2020) after preprocessing. Then, the net coastline movement distance is calculated to assess the Jiaozhou Bay reclamation intensity, and wetland information is superimposed to determine the spatiotemporal changes in wetland types. Then, the valueequivalent method is used to calculate the ESV of wetlands, and the ESV changes are analyzed from the perspective of ecological economics. Finally, we analyze the factors and their links that led to wetland changes and ecological and economic losses and provide decision-making suggestions for wetland protection. This research provides data to support the comprehensive ecological management of coastal areas, which is conducive to maximizing the utilization value of wetlands and promoting wetland protection.

\section{Study Area and Data}

\section{Study Area}

Jiaozhou Bay is adjacent to the Yellow Sea $\left(36^{\circ} 05^{\prime} 41^{\prime \prime} \mathrm{N} \sim 36^{\circ} 14^{\prime} 18^{\prime \prime} \mathrm{N}, 120^{\circ} 03^{\prime} 36^{\prime \prime} \mathrm{E} \sim 120^{\circ} 21^{\prime} 06^{\prime \prime} \mathrm{E}\right)$ and is surrounded by Qingdao city, Shandong Province, China. It is a semienclosed bay bounded to the south by Tuan Island and to the north by Xuejia Island (Fig. 1). The inner harbor of the bay is wide and deep, and the widest width from east to west is approximately $28 \mathrm{~km}$. The annual average air temperature is $12.40{ }^{\circ} \mathrm{C}$, the annual precipitation is $858 \mathrm{~mm}$, and the annual evaporation is $1136 \mathrm{~mm}$ (Shang et al. 2018). The administrative districts adjacent to Jiaozhou Bay include Huangdao District, Jiaozhou city, Chengyang District, Licang District, Shibei District and Shinan District. The seawater in Jiaozhou Bay is rich in nutrients, and 11 rivers, including the Dagu River, Moshui River, Hongjiang River and Xin' an River, enter the bay and transport large amounts of sediment and nutrients to support the Jiaozhou Bay ecosystem (Liu et al. 2005) (Fig. 1). This advantageous 
Fig. 1 Geographical map of Jiaozhou Bay (2020 Sentinel-2 data)

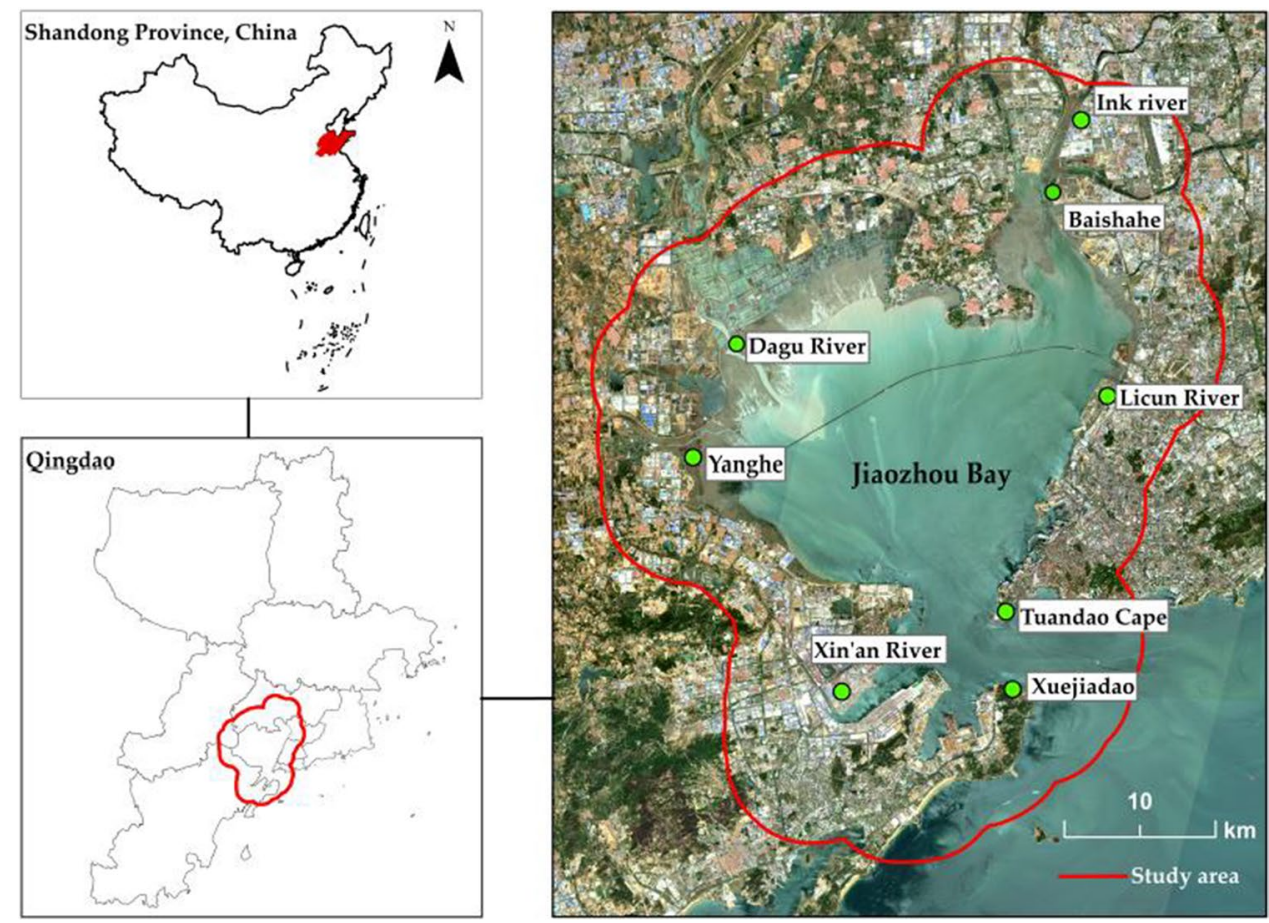

geographical location makes Jiaozhou Bay a densely populated urban area and a coastal industrial area. The demand for economic development and population growth continues to change the land use in the Jiaozhou Bay area, and the coastal economic system is an ecosystem that is highly susceptible to human disturbance (Pang et al. 2017; Gao et al. 2014; Li et al. 2014). In this paper, the 1980 coastline of Jiaozhou Bay was used as a benchmark, and a buffer zone was constructed as the study area by extending $5 \mathrm{~km}$ inland (Fig. 1).

\section{Data}

The remote sensing data were obtained from Sentinel-2 images and Landsat images downloaded from the United States Geological Survey (USGS) website (https://glovis. usgs.gov/), including Landsat Multispectral Scanner (MSS) images with a resolution of $80 \mathrm{~m}$ (in 1980), Landsat Thematic Mapper ${ }^{\mathrm{TM}}$ images with a resolution of $30 \mathrm{~m}$ (one each in 1985, 1990, 1995, 2000, 2005 and 2010), and Sentinel-2 images with a resolution of $10 \mathrm{~m}$ (in 2015 and 2020). The selected images were obtained on days with little cloud cover in the study area at low tide. The data used for ESV estimation included Qingdao's grain output per unit, the annual raw salt output, the national retail price index, total precipitation and the annual average temperature. These data were mainly obtained from the Qingdao Statistical Yearbook and the China Price Information Network, and public data were obtained from the Bulletin of Qingdao Hydrological Bureau and other platforms.

\section{Methods}

ENVI 5.3 software was used to perform image preprocessing, such as radiometric calibration, fast line-of-sight atmospheric analysis of spectral hypercubes (FLAASH) atmospheric correction (Bidorn and Rukvichai 2018), image registration and image stitching; additionally, it was used to extract the coastline and wetland data for the study area based on an object-oriented method of multiscale segmentation. The net shoreline movement (NSM) was calculated using coastlines in different periods to study the changes in coastlines (Bidorn and Rukvichai 2018; Muskananfola and Febrianto 2020). In wetland extraction, the index method was first used to distinguish between water bodies and nonwater bodies, and then, through the objectoriented method, various types of wetlands were extracted based on the characteristics of the spectra and shapes of water bodies. The tidal flats in nonwater body areas were extracted by superimposing the vector data for the coastline and the lowest tidal edge line; combined with the corresponding remote sensing images for the period, the data were visually interpreted and revised. A combination of the value-equivalent method and market value method was used to obtain various types of ESVs for different wetland types (Lin et al. 2019). The Jiaozhou Bay wetland ESV was assessed and a change analysis was performed to explore the wetland change process and corresponding influential factors. The specific technical approach used in this research is shown in Fig. 2. 
Fig. 2 Technical flow chart of the method applied in this paper

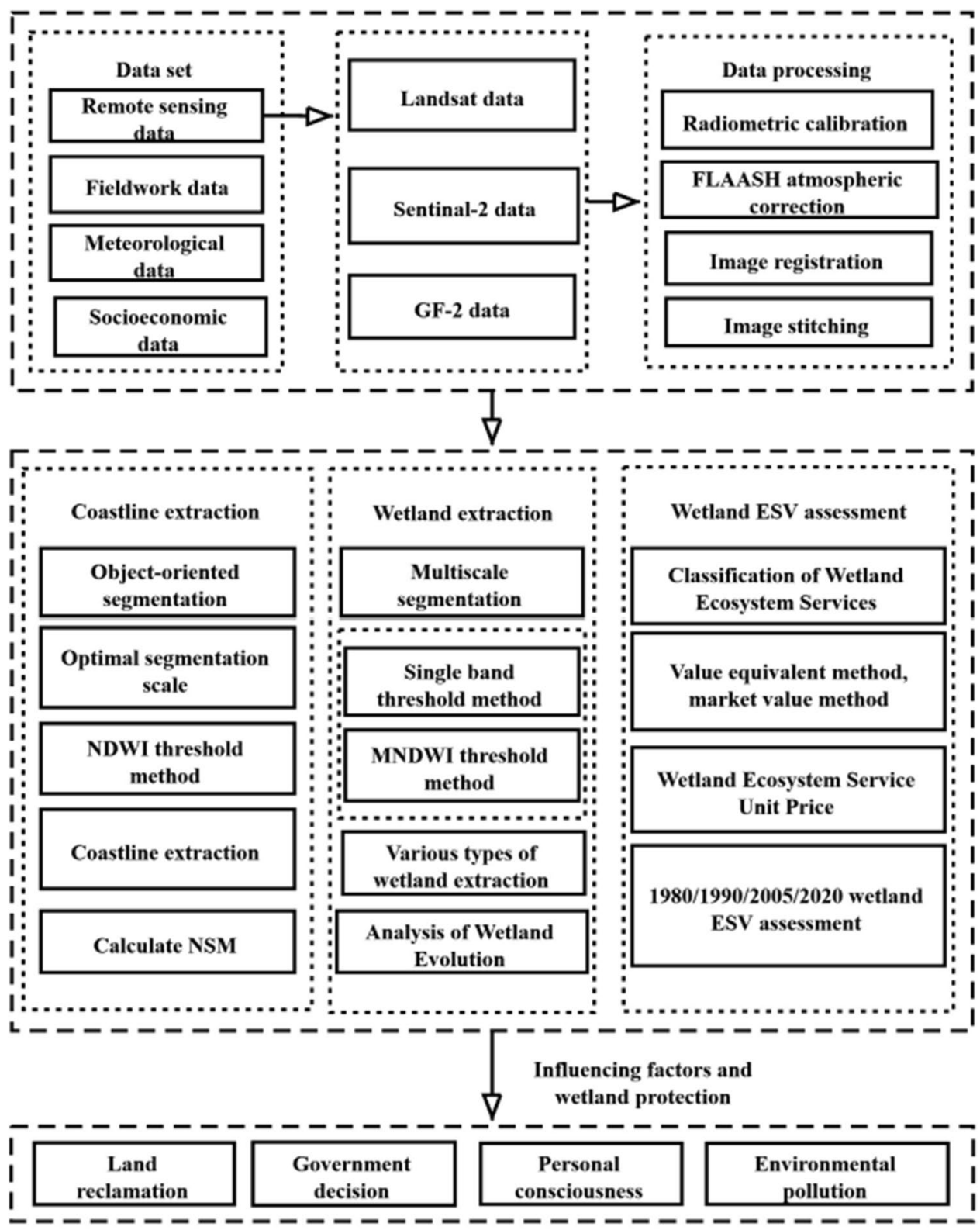

\section{Coastline Extraction}

The coastline generally refers to the line connecting the sea and extreme land positions (Kermani et al. 2016), and the dry and wet divide in low-resolution images denotes the coastline (Moore 2000). Coastline types can be mainly divided into natural coastlines and artificial coastlines. Artificial coastlines include artificially modified coastlines, such as constructed dikes, wharf dikes, traffic dikes, salt pan dikes, and breeding dikes. In this paper, object-oriented segmentation and the exponential threshold method are used to extract coastlines (Fig. 2), and the geometric and spatial features of pixels are exploited to extract ground features. First, the estimation of scale parameter 2 (ESP2) in eCognition 9.0 software was used to determine the optimal segmentation scale, shape factor, and compactness factor, which were $120,0.1$ and 0.5 , respectively. A multiscale segmentation algorithm was used to segment images into reasonable units. Second, the normalized difference water index (NDWI) threshold method was used to divide land and water boundaries (Özpolat and Demir 2019). Coastline vector data for 9 periods (every 5 years from 1980 to 2020) were obtained through visual revisions combined with remote sensing images for the corresponding periods. Rocky shorelines were used to identify the boundary between dry and wet regions in images, and estuarine shorelines were defined as the smooth transition regions between river channels and the sea. Third, the coastlines were superimposed in ArcGIS 10.6 software to draw coastline vector change diagrams. An NSM analysis from 1980 to 2020 was conducted with the 
Digital Shoreline Analysis System (DSAS) tool in ArcGIS, and the coastline space movement distance during the study period was calculated.

\section{Wetland Extraction}

The types of wetlands in the Ramsar Convention include all lakes, rivers, aquifers, swamps, wet grasslands, peatlands, oases, estuaries, deltas, tidal flats, mangroves and other coastal areas, coral reefs and all artificial sites, such as fishponds, rice fields, reservoirs and salt pans. Cowardin et al. classified wetlands as coastal wetlands (Cowardin et al. 1979), estuary wetlands (including tidal swamps and mangrove swamps), lakes, rivers, and swamps based on their origin, geographical location and ecological characteristics. In the Qingdao wetland survey, wetlands are roughly divided into offshore and coastal wetlands, river wetlands, swamp wetlands, and artificial wetlands (Guo and Zhang 2019). Based on previous studies on wetland classification combined with the Ramsar Convention on wetlands and a field investigation in the Jiaozhou Bay area, a classification system for the Jiaozhou Bay wetland was established, as shown in Table 1.

To describe the specific process of wetland extraction, wetland extraction for 2020 was used as an example. The 2020 wetland extraction process was based on Sentinel-2 imagery, with a total of 9 spectral bands providing feature variables for object-oriented classification. Wetland types except for tidal flats have large water volumes. The modified normalized difference water index (MNDWI) can be used as a feature variable for object-oriented classification (Fig. 2) (Ma et al. 2020; Wang et al. 2020), and salt pans display obvious shape characteristics, mainly shaped as contiguously distributed and regular rectangles. eCognition 9.0 can be used to extract the aspect ratios and rectangularity features of segmented objects; thus, texture features were also used during classification (Wang et al. 2019a, b; Zhao et al. 2020). Based on these characteristic variables, according to the interpretation of each wetland type (Fig. 3), samples were selected from the images for object-oriented remote sensing classification. The classification results were compared with the 2020 GF-2 images, and the misclassified areas were visually revised. Based on this classification process, wetland classification information for nine periods (1980/1985/1990/1995/2000/2005/2 010/2015/2020) was sequentially obtained. The classification results for the early high-resolution images, which were lacking, could be modified to some extent by referring to the later revised images.

The accuracy of the wetland classification results was verified through a confusion matrix, user's accuracy and the kappa coefficient (Powers 2011), and the verification of the Jiaozhou Bay wetland classification results in 2020 was used as an example. In total, 1000 samples were randomly selected within the study area, and the accuracy was verified by comparing random samples from the classification results and the actual class types in Google Earth high-resolution images and GF-2 images (Miller and Yool 2002).

Table 1 Wetland classification system for Jiaozhou Bay

\begin{tabular}{|c|c|c|}
\hline First class & Second class & Description \\
\hline \multirow[t]{3}{*}{ Artificial wetlands } & Mariculture & Fish and shrimp breeding ponds \\
\hline & Salt pans & Land for drying salt ponds and salt quarries \\
\hline & Reservoirs and ponds & $\begin{array}{l}\text { Artificial wetlands constructed/renovated for water storage and power generation, as well as ponds } \\
\text { repaired/reconstructed for freshwater aquaculture }\end{array}$ \\
\hline \multirow[t]{2}{*}{ Natural wetlands } & Tidal flats & $\begin{array}{l}\text { General term for beaches, river beaches and lake beaches that refers to the tidal flood zone between } \\
\text { the high tide level and low tide level for coastal tides, the beach land between the normal water } \\
\text { level of rivers and lakes and the flood level, and the beach land below the flood level for seasonal } \\
\text { lakes, rivers, reservoirs, and ponds. This class refers to the area of beach land between the normal } \\
\text { storage level and the maximum flood level. }\end{array}$ \\
\hline & Estuary waters & $\begin{array}{l}\text { Permanent water area from the tidal zone boundary near the mouth section (zero tidal range) to the } \\
\text { freshwater edge of the outer seashore section }\end{array}$ \\
\hline
\end{tabular}

Fig. 3 Interpretation map of wetland types (in the Sentinel-2 image): (a) mariculture; (b) salt pans; (c) reservoir ponds; (d) tidal flats; and (e) estuary waters

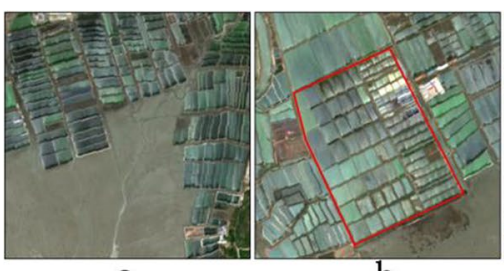

a b

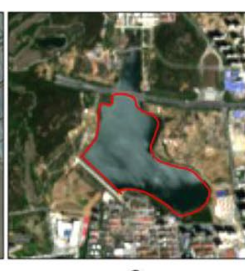

C
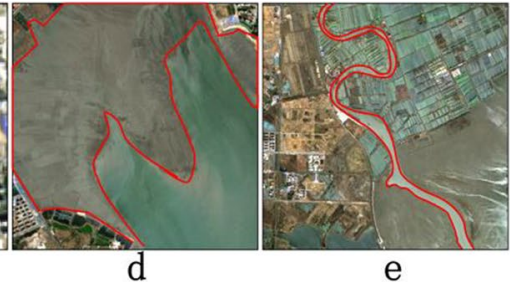


\section{ESV Estimation of Wetlands}

Using the Millennium Ecosystem Assessment method and considering the characteristics of the Jiaozhou Bay wetland, the wetland ecosystem service system was divided into 4 categories and 10 indicators (Lin et al. 2019): supply services (food production, water supply, and raw materials), regulation services (climate regulation, waste treatment, gas regulation, and hydrological regulation), support services (habitat/refuges and genetic diversity), and cultural services (leisure and entertainment) (Table 2). One standard unit ESV equivalent factor is the annual natural grain output value of 1 ha (hectare) of farmland (Xie et al. 2017), which is based on the grain (wheat and corn) yield and the average grain price in the corresponding year in Qingdao. Additionally, the value-equivalent per unit area, which is equal to a unit area with $1 / 7$ of the value of food provided by farmland, was calculated to obtain the unit value equivalent in the corresponding year in the study area, where $1 / 7$ was the naturalstate value excluding human interference. Xie et al. (Xie et al. 2015) introduced the annual average temperature and annual precipitation and used the Thornthwaite Memoria model to calculate the net primary productivity (NPP) of the biological community to revise the biomass (Whittaker and Likens 1973; Yin et al. 2020). The formula is as follows:

$N P P=300\left[1-e^{-0.0009695(V-20)}\right]$

where NPP $\left(\mathrm{t} / \mathrm{hm}^{2}\right)$ is the net primary productivity of the plant community in the study area; $\mathrm{V}$ is the actual annual evaporation, with $V=1.05 \mathrm{pre} /\left[1+(1.05 \mathrm{pre} / \mathrm{L})^{2}\right]^{1 / 2}$ ; $\mathrm{L}(\mathrm{mm})$ is the average annual evapotranspiration, with
$L=3000+25 \operatorname{Tm} p+0.05 \operatorname{Tm}^{3}$; and $\operatorname{Tmp}\left({ }^{\circ} \mathrm{C}\right)$ is the annual average temperature.

The formula used to estimate the total value of wetland ecosystem services is as follows (Costanza et al. 1997; Sannigrahi et al. 2019):

$E S V=\Sigma A_{i} \cdot V C_{i j} \cdot S_{k}$

where ESV is the total value of wetland ecosystem services; $A_{i}$ is the area of wetland type $i$ in the study area; $V C_{i j}$ is the ESV per unit area of wetland type $i j$, which is the product of the value-equivalent factor and value equivalent per unit area; and $S_{k}$ is the biomass revision coefficient in the study area, which is the ratio of the NPP of the plant community to the national average primary productivity of the plant community. The revised value-equivalent table for the study area is shown in Table 2. The prices calculated in this paper are based on the national retail price index and were used to convert the various wetland ESVs in 1980, 1990 and 2005 into comparable prices in 2020 to ensure the comparability of the annual calculation results.

\section{Results}

\section{Evaluation of the Wetland Classification Accuracy}

The accuracy verification results show that the overall classification accuracy reached $98.1 \%$ and that the kappa coefficient was 0.98 (Table 3). The spatial resolution of Landsat MSS in 1980 and 1985 was relatively low. Based on a comparison with later classification results and using the method of visual interpretation to revise areas that were

Table 2 ESV equivalent table for wetlands (per unit area: $1 \mathrm{ha}$ )

\begin{tabular}{llllll}
\hline Ecosystem type & Supply services & & \multicolumn{3}{c}{ Support services } \\
& Food production & Water supply & Raw materials & Habitat & Genetic diversity \\
Tidal flats & 0.51 & 2.59 & 0.50 & 2.31 & 7.87 \\
Estuary waters & 0.8 & 8.29 & 0.23 & 0.93 & 2.55 \\
Salt pans & 0.00 & 0.00 & $*$ & 0.93 & 0.00 \\
Mariculture & 1.36 & -2.63 & 0.09 & 0.41 & 0.21 \\
Reservoirs and ponds & 0.53 & 0.00 & 0.35 & & 3.43 \\
Ecosystem type & Regulation services & & & Hydrological regulation & Leisure and entertainment \\
& Climate adjustment & Waste disposal & Gas regulation & 4.73 \\
Tidal flats & 0.17 & 1.90 & 24.23 & 1.89 \\
Estuary waters & 3.60 & 5.55 & 0.77 & 102.24 & -7.20 \\
Salt pans & 2.29 & 0.00 & 0.00 & 2.72 & 0.00 \\
Mariculture & 0.00 & 0.17 & 1.11 & 18.77 & 0.09 \\
Reservoirs and ponds & 2.06 & 14.85 & 0.51 & 4.44 \\
\hline
\end{tabular}

Note: *The raw material service function equivalent for salt field wetlands is 0 in many studies. As Qingdao is the birthplace of sea salt, the ecological service value of the raw materials provided by the production of raw salt cannot be ignored in this study. Therefore, in this article, the service value of the raw material ecosystem provided by the salt field is calculated based on the market value method 
Table 3 Accuracy evaluation of the Jiaozhou Bay wetland classification results in 2020

\begin{tabular}{|c|c|c|c|c|c|c|}
\hline & Mariculture & Estuary waters & $\begin{array}{l}\text { Reservoirs } \\
\text { and ponds }\end{array}$ & Tidal flats & Salt pans & $\begin{array}{l}\text { User's } \\
\text { accuracy } \\
(\%)\end{array}$ \\
\hline Mariculture & 212 & & & 2 & 6 & 96.4 \\
\hline Estuary waters & 2 & 187 & & 9 & & 98.9 \\
\hline Reservoirs and ponds & & & 107 & & & 100.0 \\
\hline Tidal flats & 3 & 2 & & 329 & & 98.5 \\
\hline Salt pans & 4 & & & & 146 & 97.3 \\
\hline Producer's accuracy (\%) & 95.9 & 98.9 & 100 & 99.4 & 96.1 & \\
\hline Overall accuracy (\%) & 98.1 & & & & & \\
\hline Kappa coefficient & 0.98 & & & & & \\
\hline
\end{tabular}

misclassified in 1980 and 1985, the overall accuracy was improved. Notably, the overall accuracy values were $90 \%$ and $91.3 \%$, which met the needs of this research. During the classification process, salt pans and marine aquaculture areas exhibited similar shapes and spectral characteristics, resulting in a slightly lower classification accuracy for these two types of wetlands and a higher classification accuracy for the remaining types.

\section{Coastline Changes and Wetland Reclamation}

Over the past 40 years, the length of the Jiaozhou Bay coastline has displayed a decreasing trend, from $146 \mathrm{~km}$ in 1980 to $132 \mathrm{~km}$ in 2020 (Fig. 4b). The coastline changes from 1985 to 2010 mainly occurred in the southwest and east, and the natural coastline was transformed into an artificial regular coastline. From 1995 to 2000, the expansion of ports in southwestern Jiaozhou Bay increased the length of the artificial shoreline. The coastline changes from 2010 to 2015 were mainly manifested in the expansion of the land in the northwest to the sea, and the rate of conversion of natural coastline to artificial coastline reached $171 \%$. As of 2020 , the natural coastline in Jiaozhou Bay totaled only $14.3 \mathrm{~km}$, accounting for $10.8 \%$ of the total coastline.

Over the past 40 years, the coastline position of Jiaozhou Bay has been continuously advancing toward the sea, which is an intuitive manifestation of the coastal reclamation status (Fig. 4). The total coastal reclamation area reached $75.2 \mathrm{~km}^{2}$, indicating that approximately $23 \%$ of the area of Jiaozhou Bay has eroded. The southwest coastline extends farthest to the sea, approximately $2.6 \mathrm{~km}$ (Fig. 4e), with an average extension rate of $65 \mathrm{~m} /$ year and a reclaimed area of $32.8 \mathrm{~km}^{2}$. Over the study period, the strongest reclamation was observed in the 1980-2010 period, with a rate of
Fig. 4 Coastline changes and wetland reclamation in Jiaozhou Bay from 1980 to 2020. a: Coastline changes from 1980 to 2020; b: coastline length change map; c: region i NSM map; d: region ii NSM map; e: region iii NSM map; and f: wetland reclamation change map

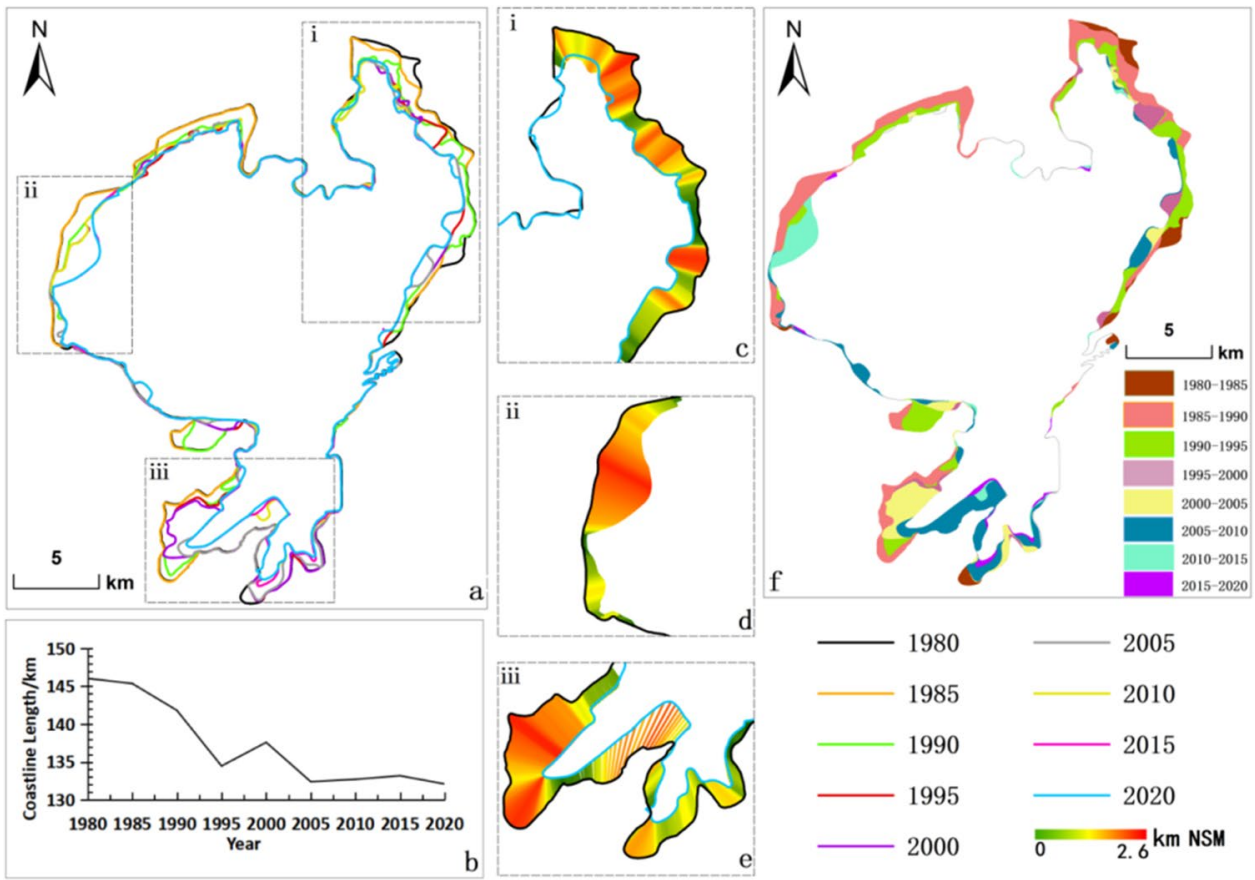


approximately $1 \mathrm{~km}^{2} /$ year, and reclamation activities weakened between 2010 and 2020. The northwestern coastline extended at a speed of approximately $67.5 \mathrm{~m}$ /year over approximately $2 \mathrm{~km}$, and the reclaimed area was approximately $7.9 \mathrm{~km}^{2}$ (Fig. 4d). The coastline of northeastern Jiaozhou Bay has extended to the sea at a slower rate, with an extension distance of approximately $1.9 \mathrm{~km}$ and a total reclamation area of $19.69 \mathrm{~km}^{2}$ (Fig. 4c). River channel expansion and ring road construction from 1990 to 2010 were the important reclamation activities that influenced the trends in the northeast.

\section{Wetland Changes}

Over the past 40 years, the total area of wetland degradation in Jiaozhou Bay has reached approximately $140.6 \mathrm{~km}^{2}$, with a degradation rate of $3.5 \mathrm{~km}^{2} /$ year. The change in area used was calculated based on the value in 2005, with the change increasing slowly in the early period and decreasing sharply in the later period (Fig. 5). From 2005 to 2020, the wetland area decreased by approximately $115 \mathrm{~km}^{2}$, and the loss rate reached $48.8 \%$. Both natural wetlands and artificial wetlands suffered different degrees of loss. The rate of decrease of natural wetlands was the largest between 1985 and 1990, reaching $28.1 \%$, and the area of artificial wetlands increased sharply during this period. After 2005, the artificial wetland area decreased by approximately $98.2 \mathrm{~km}^{2}$, with a reduction rate of $70.1 \%$; most wetlands were converted to nonwetlands. During the study period, the tidal flats expanded to the sea, but their area decreased from $115 \mathrm{~km}^{2}$ in 1980 to $54 \mathrm{~km}^{2}$ in 2020, a loss of 53\%. Landfills in mariculture areas and salt pans were reduced in area to $58 \mathrm{~km}^{2}$ and $41 \mathrm{~km}^{2}$, respectively, resulting in a decrease in artificial wetlands. The wetlands that disappeared were transformed into urban residential areas and construction land for industrial and mining transportation, causing serious ecological and economic losses.

From the perspective of the succession direction, the most significant wetland succession trend was the transition from artificial wetlands to nonwetlands in the northern part of Jiaozhou Bay, with a conversion area of $79.6 \mathrm{~km}^{2}$ (Fig. 6); notably, aquaculture wetlands were reduced in area by 49.1\%. Excluding the mariculture area in the Hongdao Economic Zone, which has been partially retained thus far, the entire mariculture area in the northeast corner of Jiaozhou Bay has been converted into construction land. Only $0.6 \mathrm{~km}^{2}$ of nonwetland was converted into artificial wetland. In sharp contrast, $23.2 \mathrm{~km}^{2}$ of natural wetland was converted into artificial wetland. Figure 5 shows that the transformation of natural wetlands was mainly caused by human activities, such as reclamation projects along beach wetlands and aquaculture reclamation. Although strict wetland protection measures were implemented in the core area of Jiaozhou Bay after 2000 and illegal breeding facilities were largely eradicated, only $20 \%$ of the tidal flat area was restored.

The environmental status of the adjacent estuary has directly affected the ecological environment of Jiaozhou Bay, and a detailed analysis of the estuary wetland is conducive to gaining a comprehensive understanding of the wetland ecology. At the beginning of 1980, the estuary of Jiaozhou Bay was dominated by natural wetlands and natural shorelines. With population growth and economic development, several wetlands were replaced with artificial construction land (Fig. 6). For example, $7.2 \mathrm{~km}^{2}$ of natural wetlands in the estuary of the Xin' an River and $1.4 \mathrm{~km}^{2}$ of salt field wetlands were developed into industrial zones for marine logistics, oil development, and container storage. The estuaries of the Hongjiang River, Moshui River, Xiangmao River and Baisha River in the northeastern part of Jiaozhou Bay experienced dynamic changes in mariculture areas. From 1980
Fig. 5 Changes in the area of various wetland types from 1980 to 2020

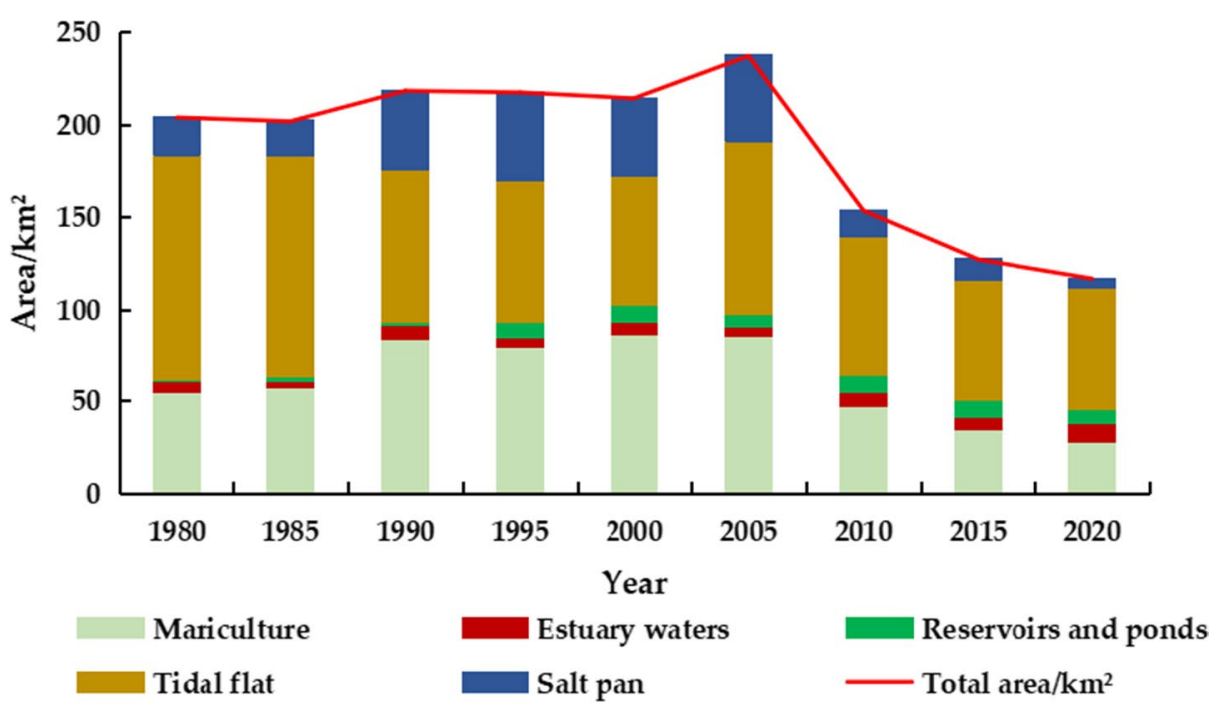


Fig. 6 Estuarine wetland changes in Jiaozhou Bay

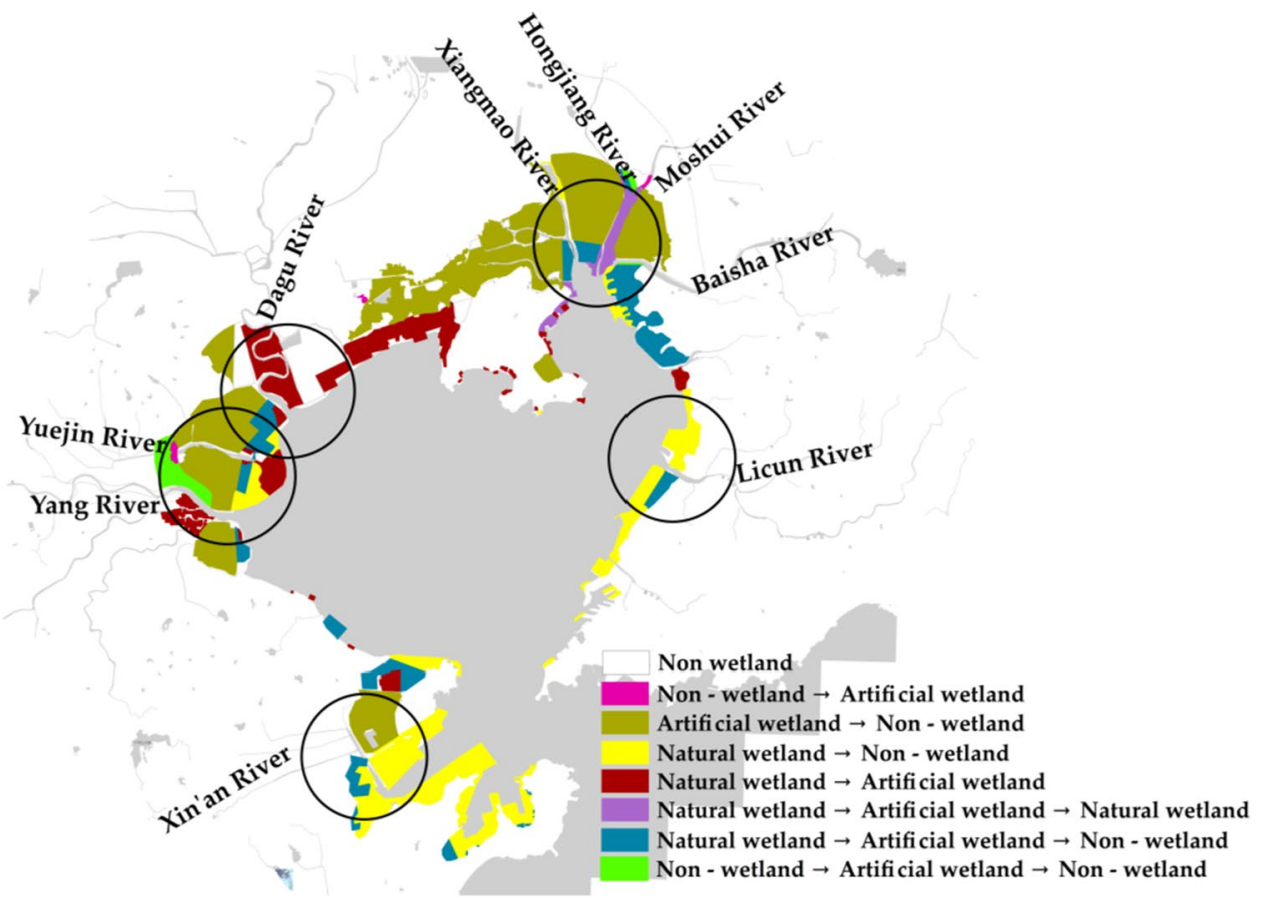

to 1995 , mariculture areas converged in the estuary at a rate of $0.7 \mathrm{~km}^{2} /$ year and expanded toward the sea, and the area reached $10.6 \mathrm{~km}^{2}$. From 1995 to 2010 , the development of the Hongdao Economic Zone and expansion of the Moshui River and the Hongjiang River caused $38.8 \mathrm{~km}^{2}$ of marine aquaculture areas and salt pans to be landfilled, reflecting an artificial wetlands $\rightarrow$ nonwetlands change process. The Dagu River Estuary wetland is in the core wetland area of Jiaozhou Bay under protection and provides certain basic ecological resources, and tidal flat breeding and reclamation activities continue to occur on both sides of this wetland. The comprehensive treatment project of the Yanghe River and the river rehabilitation project of the Yuejin River for flood storage and landscape functions have reduced the marine aquaculture area in the surrounding wetlands at an average rate of $3.3 \mathrm{~km}^{2} /$ year. Additionally, the artificial wetlands have been converted into residential and commercial areas. For nonwetlands, the landfill area of these projects reached $49.9 \mathrm{~km}^{2}$ by 2015 . This change was the direct cause of the extension of northwestern Jiaozhou Bay to the sea.

\section{Changes in the Wetland Ecological Service Value}

From the perspective of ecological economics, the total ESV of the coastal wetland of Jiaozhou Bay has continued to increase over the past 40 years, with a rate of increase of approximately $114.6 \%$ (Table 4 ). The total ESV of all wetland types except salt pans increased, and the ESV of tidal flat wetlands accounted for the largest proportion of the total value, accounting for $65.5 \%$ in 2020 . Since 2005 , the continuous management of estuarine waters has created estuarine wetlands with strong ecological functions and an ecological value of 33 million USD (Table 4); additionally, in the last 15 years, the genetic diversity and leisure and entertainment service values have increased by $233.2 \%$ (Table 5). The ecological service function of salt pans is low (Table 4), and the value of raw material supply services has been declining annually. The negative effects of hydrological regulation services have become increasingly serious. Consequently, the total ESV of salt pans decreased by $108.7 \%$, and the largest decrease between 1990 and 2005 was $88.7 \%$ (Table 4). The food supply value of mariculture increased linearly, the negative value of water supply and the value of raw material supply first decreased and then increased, and the values of genetic diversity, habitat, and leisure and entertainment services first increased and then decreased (Table 5).

The ESV types were as follows: regulation services $>$ support services $>$ supply services $>$ cultural services. The value of regulation services accounted for more than $69 \%$ of the total wetland value, and the value of cultural services increased. This result is consistent with the research results of Shang Huimin from 2005 to 2015 (Shang et al. 2018). Additionally, hydrological regulation accounted for more than $47 \%$ of the total value of regulation services and is the core function of Jiaozhou Bay wetland ecological services. Genetic diversity accounted for more than $11 \%$ of the total ESV. 


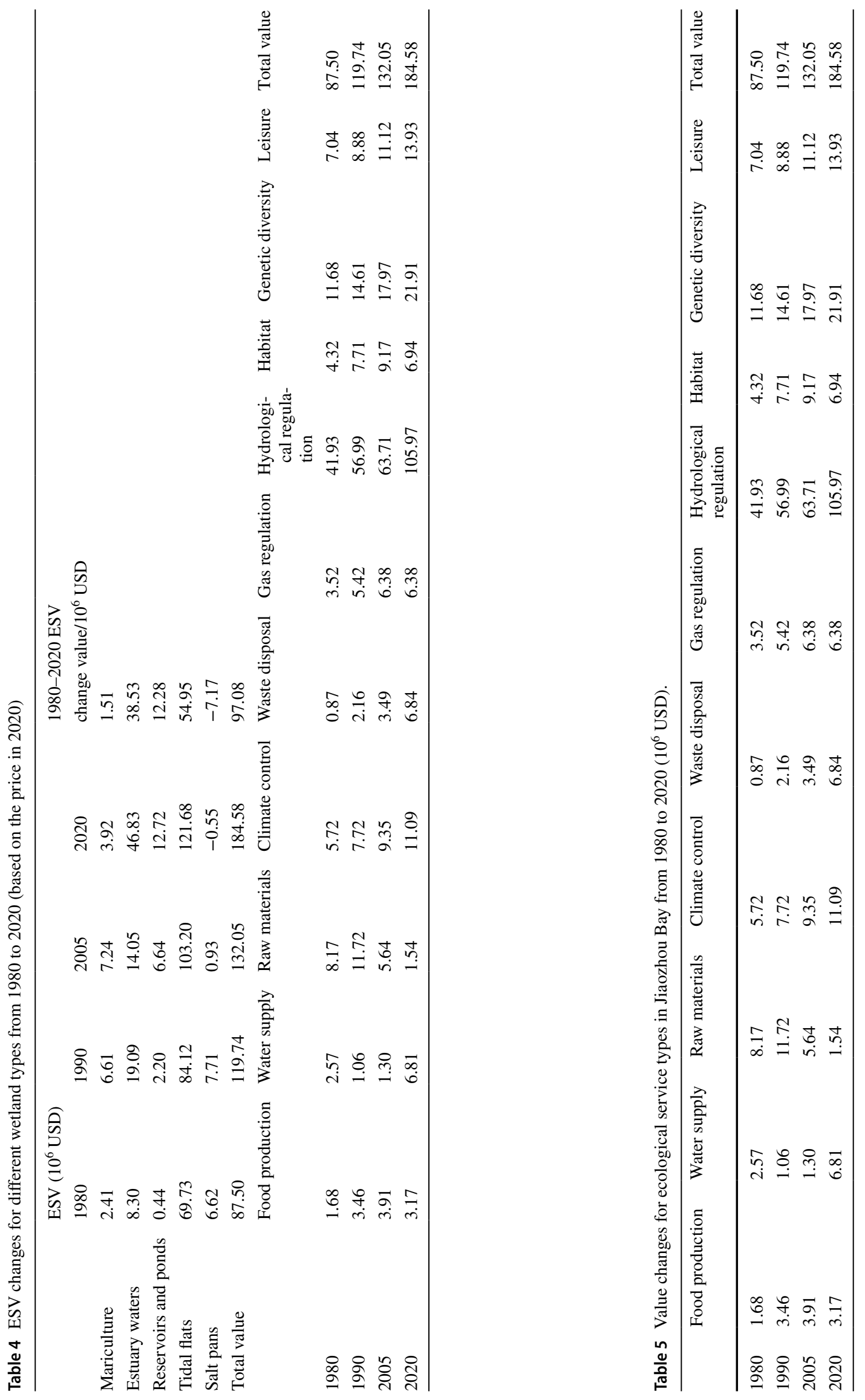




\section{Discussion}

\section{Wetland Ecological Destruction and Influencing Factors}

The continuous reclamation of wetlands has led to the gradual shrinkage of Jiaozhou Bay (Ma et al. 2008; Li et al. 2015; Xie et al. 2012), the weakening of seawater dynamics, the destruction of benthic habitats and a reduction in biodiversity (Shi et al. 2011). The regulatory function of Jiaozhou Bay has gradually been impaired, the water exchange capacity has weakened, and the exchange capacity of pollutants in the bay has deteriorated (Li et al. 2015; Xie et al. 2012; Zhang 2004). The input from rivers is one of the factors that has affected the wetland environment. The industrial wastewater and domestic sewage transported by the Moshui River are the main sources of organic nitrogen in Jiaozhou Bay, causing the dissolved inorganic nitrogen levels along the coast of Jiaozhou Bay to exceed the relevant standard (Liu et al. 2005; Shen 2001). The Dagu River has had the highest phosphorus input, and the Licun River has been affected by urban governance and has had a low nutrient input load (Yuan et al. 2016). From 1990 to 2000, seawater eutrophication in Jiaozhou Bay was severe, and the nitrogen and phosphorus burial fluxes increased, destroying the ecological environment in the bay (Liu et al. 2005; Turner 2002). At present, with the increased awareness regarding the protection of Jiaozhou Bay, land-based pollution, such as by domestic sewage, industrial wastewater and agricultural fertilizers, has been controlled, and the environment in Jiaozhou Bay has displayed a positive trend with increasing economic growth.

Land reclamation is the factor most directly causing coastal wetland degradation and coastline changes $(\mathrm{Gu}$ et al. 2007), and urbanization plays an important role in wetland ESV changes (Qi et al. 2020). The increase in coastal construction land, human activities such as river damming and drainage projects, and the construction of the Jiaozhou Bay Bridge have caused the coastline to extend into the sea, and the tidal flat area has considerably changed. In other bays around the world, such as Tampa Bay in the United States and the Gulf of Thailand, coastal change has originated from large-scale human development activities and resulted in an astonishing loss of wetland area and serious ecological deterioration; consequently, the recognition and protection of the value of wetlands have increased (Guo et al. 2019).

Among the wetland types in Jiaozhou Bay, tidal flat wetlands have provided the most value for functioning services, support services and cultural services, and the wetland ESV has changed. During the study period, pollution from land-based wastewater discharge in Jiaozhou Bay affected the water quality in the bay. At the end of the twentieth century, frequent oil spills and heavy metal pollution along the coast of Jiaozhou Bay caused great harm to the seawater and mariculture industry in the bay (Qian et al. 2009; Sun et al. 2018). With the implementation of the "Salt Field Reconstruction and Construction Plan" in Jiaozhou Bay, the quality of the Dagu River, the Moshui River and other inland rivers has improved. Control of land source inputs has been the focus of efforts to maintain the environmental quality of the bay and increase the area of high-quality water. Therefore, it is necessary to maintain the sustainable development of the environment in conjunction with economic growth. Additionally, wetland policy has shifted from an economic focus to an ecological focus (Suzuki 2003).

\section{Synergetic Relationship between ESV Changes and Wetlands}

The ESV and wetland area have had both a synergistic relationship and a trade-off effect in different periods (Ma et al. 2020), and this result is mainly due to the creation of another ecosystem service by changing wetland types. During the study period, Jiaozhou Bay experienced a $7 \%$ increase in wetland area from 1980 to 1990 and a $36.8 \%$ increase in the ESV (Table 5). From 1990 to 2005, the wetland area increased by $8.6 \%$, and the ESV increased by $10.3 \%$. In the past 40 years, the value of leisure and entertainment services has doubled, and the value of cultural services has continued to increase (Shang et al. 2018). Jiaozhou Bay's tourism industry exploits the advantages of coastal tourism resources, and multimodal integration with other cultures has increased the cultural service value of coastal wetlands. Since the twenty-first century, salt pans have been landfilled in large areas, and their output decreased from 110,000 tons/ year in 2005 to 12,800 tons/year in 2013. These results suggest that there is a synergistic effect between ESV changes and wetland area changes. An increase in wetland area will improve the ecological environment and increase the value of ecosystem services.

The wetland area declined rapidly after reaching its peak in 2005 , and by 2020 , it had decreased by $48.8 \%$. During this period, the value of ecological services continued to increase by $42.3 \%$. Many mariculture areas were landfilled after 2005 , with the area decreasing by $67.4 \%$, but the value of the corresponding food supply did not decline. The ESV changes and wetland area changes displayed a trade-off relationship. The most direct reason for this relationship was that land reclamation activities in the northern part of Jiaozhou Bay were limited after 2005; additionally, the loss of tidal flats gradually slowed, thus enhancing ecosystem services (Fig. 5). Many salt pans and mariculture ponds 
were landfilled, leading to a decrease in water consumption. With the successive establishment of Jiaozhou Bay National Marine Park and National Wetland Park, the function of the wetland ecosystem was restored (Qin and Zhang 2021). These factors played a positive role in increasing the ESV. Indirect influential factors include the realization of the value of wetland ecosystem services, the improvement in people's recognition of wetlands, the standardization and rationalization of marine aquaculture practices and the development of intertidal tidal flats. Moreover, the spread of COVID-19 and international economic and trade frictions in late 2019 affected international and domestic food prices, leading to a $2020 \mathrm{ESV}$ equivalent factor higher than the ESV equivalent factors in other years. The rise in food prices has stimulated the recovery of aquaculture and increased the value of seafood production.

\section{Ecological Protection Measures}

The tidal flat area of Jiaozhou Bay accounts for the largest proportion of the bay's wetland area, and the created ESV is also relatively large. Therefore, the ecological protection of the Jiaozhou Bay wetland is mainly achieved by protecting tidal flats. Reclamation should be reduced, and illegal reclamation activities should be fully prevented (Spencer et al. 2016). Wetland tourism is also an important way to rationally use wetland resources (Aazami and Shanazi 2020), increase the number of environmental protection personnel in scenic spots, strictly control garbage pollution, and promote the protection of wetland resources. Artificial breeding models should focus on sustainable development, water quality should be improved while maintaining the diversity of benthic animals, new breeding technologies should be developed, and the breeding output should be increased considering wetland area limitations. The use of agricultural fertilizers should be biased toward pollution-free green ecological series as much as possible, sources of polluted water in estuary wetlands should be evaluated and the direct flow of pollutants into Jiaozhou Bay should be reduced because this pollution affects water quality. The current Jiaozhou Bay wetland management system is one in which the forestry department takes the lead and other departments participate. To generate a mature wetland management system, a special department should be established for wetland management, and special legislation should also be formulated to enhance awareness of wetland protection. When formulating wetland management strategies, increased attention should be given to natural wetland product development and wetland industry development. Through the ecological protection measures above, the scientific use of wetland resources can be improved, and the coordinated development of wetland ecosystem services can be promoted (Sutton-Grier et al. 2015).

\section{Conclusion}

Wetland degradation will cause the continuous destruction of wetland ecological structures and functions and severe losses in the value created by wetland ecosystems. This paper uses multispectral satellite imagery to study the reclamation of the Jiaozhou Bay wetland over the past 40 years and the changes in the wetland ESV. In this study, the classification of wetlands is specific, and the accuracy of information extraction is high. We provide typical regional cases for wetland change research and the corresponding data to support the comprehensive ecological management of coastal areas.

Over the past 40 years, the coastline of Jiaozhou Bay has continuously advanced into the sea. The total coastal reclamation area has reached $75.2 \mathrm{~km}^{2}$, indicating that approximately $23 \%$ of the area of Jiaozhou Bay has eroded. From 2005 to 2020 , the wetland area decreased rapidly by $48.8 \%$, which was mainly manifested in the transformation of artificial wetlands to nonwetlands, especially the conversion of marine aquaculture areas and salt pans into construction land. The total ESV of the coastal wetland of Jiaozhou Bay has continued to increase over the past 40 years. Among the local wetland types, tidal flats have the largest ESV, accounting for $65.5 \%$ of the total ESV in 2020.

Therefore, the ecological protection of the Jiaozhou Bay wetland is mainly based on protecting tidal flats. The environmental conditions of the estuary directly affect the ecological environment of Jiaozhou Bay. Since 2005, the continuous improvement of estuarine waters has created an ecological value of 33 million USD in estuarine wetlands, with strong ecological functions over the past 15 years. In addition, reducing reclamation work and stopping illegal reclamation activities are necessary tasks for ensuring that the area of the bay is no longer shrinking. A mature wetland management system should be established, the development of natural wetland products and the wetland industry should receive increased attention, and the coordinated development of the wetland ecosystem should be achieved.

Acknowledgments We appreciate the critical and constructive comments and suggestions from the reviewers, which helped improve the quality of this manuscript. We would also like to offer our sincere thanks to those who participated in data processing and provided constructive comments on this study.

Author Contributions Conceptualization, J.Y., F.S., and J.D.; formal analysis, J.D. and S.Z. (Shiyi Zhao); funding acquisition, J.Y. and F.S.; methodology, J.D., S.Z. (Shiyi Zhao), P.F., and S.Z. (Shixun Zhang); writing - original draft, J.D.; and writing — review and editing, J.Y., F.S., and J.D. All authors have read and agreed to the published version of the manuscript.

Funding This research was funded by the Chinese Academy of Sciences Strategic Leading Special A "Earth Big Data Science Project" 
(XDA19060300) and the Major Science and Technology Innovation Projects of Shandong Province (2019JZZY020103).

Data Availability Statement The datasets generated during the current study are available in the figshare repository (https://figshare.com/artic les/dataset/Wetland_data_rar/18828167).

Code Availability Not applicable.

\section{Declarations}

Conflict of Interest The authors declare no conflicts of interest.

Ethics Approval Not applicable.

Consent to Participate Not applicable.

Consent for Publication Written informed consent for publication was obtained from the corresponding author.

\section{References}

Aazami M, Shanazi K (2020) Tourism wetlands and rural sustainable livelihood: the case from Iran. Outdoor Recreat Tour 30:100284. https://doi.org/10.1016/j.jort.2020.100284

An S, Li H, Guan B, Zhou C, Wang Z, Deng Z, Zhi Y, Liu Y, Xu C, Fang S, Jiang J, Li H (2007) China's natural wetlands: past problems, current status, and future challenges. Ambio 36:335-342. https://doi.org/10.1579/0044-7447(2007)36[335:cnwppc]2.0.co;2

Bidorn B, Rukvichai C (2018) Impacts of coastal development on the shoreline change of the eastern gulf of Thailand. IOP Conference Series: Earth Environ Sci 171:012007. https://doi.org/10.1088/ $1755-1315 / 171 / 1 / 012007$

Costanza R, d'Arge R, de Groot R, Farber S, Grasso M, Hannon B, Limburg K, Naeem SV, O'Neill R, Paruelo J, Raskin RG, Sutton $\mathrm{P}$, van den Belt M (1997) The value of the world's ecosystem services and natural capital. Nature 387:253-260. https://doi.org/ $10.1038 / 387253 \mathrm{a} 0$

Cowardin LM, Carter V, Golet FC, LaRoe ET (1979) Classification of wetlands and Deepwater habitats of the United States.U.S. Fish and Wildlife Service, Washington

Creighton C, Boon PI, Brookes JD, Sheaves M (2015) Repairing Australia's estuaries for improved fisheries production-what benefits, at what cost? Marine and Freshwater Research 66:493. https://doi. org/10.1071/MF14041

Crossman ND, Bryan BA (2009) Identifying cost-effective hotspots for restoring natural capital and enhancing landscape multi-functionality. Ecological Economics 68:654-668. https://doi.org/10. 1016/j.ecolecon.2008.05.003

Davidson NC (2014) How much wetland has the world lost? Long-term and recent trends in global wetland area. Marine and Freshwater Research 65:934-941. https://doi.org/10.1071/MF14173

De Groot R, Brander L, van der Ploeg S, Costanza R, Bernard F, Braat L, Christie M, Crossman N, Ghermandi A, Hein L, Hussain S, Kumar P, McVittie A, Portela R, Rodriguez LC, ten Brink P, van Beukering P (2012) Global estimates of the value of ecosystems and their services in monetary units. Ecosystem Services 1:50-61. https://doi.org/10.1016/j.ecoser.2012.07.005

Sengupta D, Chen R, Meadows M, Choi Y, Banerjee A, Xia Z (2019) Mapping trajectories of coastal land reclamation in nine deltaic megacities using Google earth engine. Remote Sensing 11(22). https://doi.org/10.3390/rs11222621
Englund O, Berndes G, Cederberg C (2017) How to analyze ecosystem services in landscapes--a systematic review. Ecological Indicators 73:492-504. https://doi.org/10.1016/j.ecolind.2016.10.009

Feingold D, Koop S, Van LK (2018) The city blueprint approach: urban water management and governance in cities in the U.S. Environmental Management 61(1):9-23. https://doi.org/10.1007/ s00267-017-0952-y

Gao G, Wang X, Bao X (2014) Land reclamation and its impact on tidal dynamics in Jiaozhou Bay, Qingdao, China. Estuarine, Coastal and Shelf Science 115:285-294. https://doi.org/10.1016/j.ecss. 2014.07.017

Glaser R, Haberzettl P, Walsh RPD (1991) Land reclamation in Singapore, Hong Kong and Macau. GeoJournal 4:365-373 http://www. jstor.org/stable/41145219

Guo Z, Zhang M (2019) The conservation efficacy of coastal wetlands in China based on landscape development and stress. Ocean and Coastal Management 175:70-78. https://doi.org/10.1016/j.oceco aman.2019.03.018

Guo Q, Pu R, Tapley K, Cheng J, Li J, Jiao T (2019) Impacts of coastal development strategies on long-term coastline changes: a comparison between Tampa Bay, USA and Xiangshan Harbor, China. Pap Appl Geogr 5:126-139. https://doi.org/10.1080/23754931. 2019.1654405

Gu D, Zhang Y, Fu J, Zhang X (2007) The landscape pattern characteristics of coastal wetlands in Jiaozhou Bay under the impact of human activities. Environmental Monitoring and Assessment 124(1):361-370. https://doi.org/10.1007/s10661-006-9232-7

Hou X, Wu T, Hou W, Chen Q, Wang Y, Yu L (2016) Characteristics of coastline changes in mainland China since the early 1940s. Science China Earth Sciences 59(9):1791-1802. https://doi.org/ 10.1007/s11430-016-5317-5

Kermani S, Boutiba M, Guendouz M, Guettouche MS, Khelfani D (2016) Detection and analysis of shoreline changes using geospatial tools and automatic computation: case of jijelian sandy coast (East Algeria). Ocean and Coastal Management 132:46-58. https://doi.org/10.1016/j.ocecoaman.2016.08.010

Lin W, Xu D, Guo P, Wang D, Li L, Gao J (2019) Exploring variations of ecosystem service value in Hangzhou Bay wetland. Eastern China Ecosyst Serv 37:100944. https://doi.org/10.1016/j.ecoser. 2019.100944

Lindley D, Lotz-Sisitka H (2019) Expansive social learning, morphogenesis and reflexive action in an organization responding to wetland degradation. Sustainability 11:4230. https://doi.org/10. 3390/su11154230

Li J, Chen Q, Yao H (2015) Evaluation of ecological benefit loss of Jiaozhou Bay wetland reclamation based on selective experiment(in Chinese). Resour Sci 37:68-75 CNKI: SUN:ZRZY.0.2015-01-009

Li P, Li G, Qiao L, Chen X, Shi J, Gao F, Wang N, Yue S (2014) Modeling the tidal dynamic changes induced by the bridge in Jiaozhou Bay,Qingdao, China. Continental Shelf Research 84:4353. https://doi.org/10.1016/j.csr.2014.05.006

Liu Y, Li J, Yang Y (2018) Strategic adjustment of land use policy under the economic transformation. Land Use Policy 74:5-14. https://doi.org/10.1016/j.landusepol.2017.07.005

Liu S, Zhang J, Chen H, Zhang G (2005) Factors influencing nutrient dynamics in the eutrophic Jiaozhou Bay, North China. Progress in Oceanography 66(1):66-85. https://doi.org/10.1016/j.pocean. 2005.03.009

Ma X, Zhu J, Zhang H, Yan W, Zhao C (2020) Trade-offs and synergies in ecosystem service values of inland lake wetlands in Central Asia under land use/cover change: a case study on Ebinur Lake, China. Glob Ecol Conserv 24:e01253. (prepublish). https://doi. org/10.1016/j.gecco.2020.e01253

Ma Y, Li G, Liu Y, Shi J (2008) Remote sensing analysis and quality evaluation of the dynamic changes of Jiaozhou Bay wetland (in 
Chinese). Marine Geology and Quaternary Geology 1:69-75. https://doi.org/10.16562/j.cnki.0256-1492.2008.01.001

Mayer-Pinto M, Cole VJ, Johnston EL, Bugnot A, Hurst H, Airoldi L, Glasby TM, Dafforn KA (2018) Functional and structural responses to marine urbanisation. Environmental Research Letters 13(1):014009. https://doi.org/10.1088/1748-9326/aa98a5

McAllister DE, Craig JF, Davidson N, Delany S, Seddon M (2001) Biodiversity Impacts of Large Dams. Background paper 1

Millennium Ecosystem Assessment (2005) Ecosystems and human well-being. Insland Press, Washington

Miller JD, Yool SR (2002) Mapping forest post-fire canopy consumption in several overstory types using multi-temporal Landsat TM and ETM data. Remote Sensing of Environment 82(2):481-496. https://doi.org/10.1016/S0034-4257(02)00071-8

Moore LJ (2000) Shoreline mapping techniques. Journal of Coastal Research 16(1):111-124

Muskananfola MR, Febrianto S (2020) Spatio-temporal analysis of shoreline change along the coast of Sayung Demak, Indonesia using digital shoreline analysis system. Regional Studies in Marine Science 34:101060. https://doi.org/10.1016/j.rsma. 2020.101060

Ochoa V, Urbina-Cardona N (2017) Tools for spatially modeling ecosystem services:publication trends, conceptual reflections and future challenges. Ecosystem Services 26:155-169. https:// doi.org/10.1016/j.ecoser.2017.06.011

Özpolat E, Demir T (2019) The spatiotemporal shoreline dynamics of a delta under natural and anthropogenic conditions from 1950 to 2018: a dramatic case from the eastern Mediterranean. Ocean and Coastal Management 180:104910. https://doi.org/10.1016/j. ocecoaman.2019.104910

Pang L, Kong F, Xi M, Li Y, Li Q (2017) Analysis on land use change in coastal zone of Jiaozhou Bay. Wetl Sci 15:680-688. https://doi.org/10.13248/j.cnki.wetlandsci.05.006

Powers DMW (2011) Evaluation: from precision, recall and F-measure to ROC, informedness, markedness and correlation. Mach Learn Technol 2:37-63 16061. http://www.bioinfo.in/contents. php?id=51

Qi J, Deng W, Zhou Y, Luo X (2020) Spatial temporal evolution and driving force of ecosystem service value in three gorges reservoir area. Yangtze River 51:113-119. https://doi.org/10. 16232/j.cnki.1001-4179.2020.01.017

Qian GD, Han H, Liu J, Liang S, Shi X, Wang X (2009) Spatiotemporal changes of main chemical pollutants for the last thirty years in the Jiaozhou Bay. Period Ocean Univ China (in Chinese with English Abstract) 39(4):781-788. https://doi.org/10. 16441/j.cnki.hdxb.2009.04.037

Qin P, Zhang Z (2021) Evolution of wetland landscape disturbance in Jiaozhou gulf between 1973 and 2018 based on remote sensing. Eur J Remote Sens 54(sup2):145-154. https://doi.org/10.1080/ 22797254.2020.1758963

Ritsch LD, Dunbar JB (1993) Land loss rates: Louisiana coastal plain. Journal of Coastal Research 9:324-338

Sannigrahi S, Chakraborti S, Joshi PK, Keesstra S, Sen S, Paul SK, Kreuter U, Sutton PC, Jha S, Dang KB (2019) Ecosystem service value assessment of a natural reserve region for strengthening protection and conservation. Journal of Environmental Management 244:208-227. https://doi.org/10.1016/j.jenvman. 2019.04.095

Shang H, Xi M, Li Y, Kong F, Wang S (2018) Evaluation of changes in the ecosystem services of Jiaozhou Bay coastal wetland. Acta Ecologica Sinica 38(2):421-431. https://doi.org/10.5846/stxb2 01608301763

Shan J, Li J (2020) Valuing marine ecosystem service damage caused by land reclamation: insights from a deliberative choice experiment in Jiaozhou Bay. Marine Policy (prepublish). https://doi.org/ 10.1016/j.marpol.2020104249
Shen Z (2001) Historical changes in nutrient structure and its influences on phytoplankton composition in Jiaozhou Bay. Estuarine, Coastal and Shelf Science 52(2):211-224. https://doi.org/10.1006/ ecss. 2000.0736

Shi J, Li G, Wang P (2011) Anthropogenic influences on the tidal prism and water exchanges in Jiaozhou Bay, Qingdao, China. Journal of Coastal Research 27(1):57-72. https://doi.org/10.2112/JCOAS TRES-D-09-00011.1

Son S, Wang M (2009) Environmental responses to a land reclamation project in South Korea. Eos Trans AGU 90(44):398. https://doi. org/10.1029/2009EO440002

Sousa CAM, Cunha ME, Ribeiro L (2020) Tracking 130 years of coastal wetland reclamation in ria Formosa, Portugal: opportunities for conservation and aquaculture. Land Use Policy 94:104544. https://doi.org/10.1016/j.landusepol.2020.104544

Spencer T, Schuerch M, Nicholls RJ, Hinkel J, Lincke D, Vafeidis AT, Reef R, Mcfadden L, Brown S (2016) Global coastal wetland change under sea-level rise and related stresses: the DIV a wetland change model. Global and Planetary Change 139:15-30. https:// doi.org/10.1016/j.gloplacha.2015.12.018

Stedman SM, Dahl TE (2008) Status and Trends of Wetlands in the Coastal Watersheds of the Conterminous United States, 1998 to 2004

Sun X, Li Y, Zhu X, Cao K, Feng L (2017) Integrative assessment and management implications on ecosystem services loss of coastal wetlands due to reclamation. Journal of Cleaner Production 163:S101-S112. https://doi.org/10.1016/j.jclepro.2015.10.048

Sun B, Tang J, Yu D, Song Z, Wang P (2019) Ecosystem health assessment: a PSR analysis combining AHP and FCE methods for Jiaozhou Bay, China. Ocean and Coastal Management 168:41-50. https://doi.org/10.1016/j.ocecoaman.2018.10.026

Sun B, Cui L, Li W, Kang X, Pan X, Lei Y (2018) A meta-analysis of coastal wetland ecosystem services in Liaoning Province, China. Estuarine, Coastal and Shelf Science 200:349-358. https://doi. org/10.1016/j.ecss.2017.11.006

Sutton-Grier AE, Wowk K, Bamford H (2015) Future of our coasts: the potential for natural and hybrid infrastructure to enhance the resilience of our coastal communities, economies and ecosystems. Environmental Science \& Policy 51:137-148. https://doi.org/10. 1016/j.envsci.2015.04.006

Suzuki T (2003) Economic and geographic backgrounds of land reclamation in Japanese ports. Marine Pollution Bulletin 47(1):226229. https://doi.org/10.1016/S0025-326X(02)00405-8

Turner RE (2002) Element ratios and aquatic food webs. Estuaries 25(4):694-703. https://doi.org/10.1007/BF02804900

Wang Y, Ma J, Xiao X, Wang X, Dai S, Zhao B (2019a) Long-term dynamic of Poyang lake surface water: a mapping work based on the Google earth engine cloud platform. J Remote Sens 11(3):0313. https://doi.org/10.3390/rs11030313

Wang X, Xiao X, Zou Z, Hou L, Qin Y, Dong J, Doughty RB, Chen B, Zhang X, Chen Y, Ma J, Zhao B, Li B (2020) Mapping coastal wetlands of China using time series Landsat images in 2018 and Google earth engine. ISPRS Journal of Photogrammetry and Remote Sensing 163:312-326. https://doi.org/10.1016/j.isprs jprs.2020.03.014

Wang Y, Liu Y, Jin S, Sun C, Wei X (2019b) Evolution of the topography of tidal flats and sandbanks along the Jiangsu coast from 1973 to 2016 observed from satellites. ISPRS Journal of Photogrammetry and Remote Sensing 150:27-43. https://doi.org/10.1016/j. isprsjprs.2019.02.001

Whittaker RH, Likens GE (1973) Primary production: the biosphere and man. Hum Ecol Interdiscip 1(4):357-369. https://doi.org/10. 1007/BF01536732

Wu W, Yan S, Feng R, Song D, Chen X (2017) Development of an environmental performance indicator framework to evaluate management effectiveness for Jiaozhou Bay coastal wetland special 
marine protected area, Qingdao, China. Ocean and Coastal Management 142:71-89. https://doi.org/10.1016/j.ocecoaman.2017. 03.021

Xie G, Zhen L, Lu C, Xiao Y, Chen C (2008) An ecosystem service valuation method based on expert knowledge(in Chinese). J Natl Resources 5:911-919 CNKI:SUN: ZRZX.0.2008-05-019

Xie W, Li X, Yu R, Cui Y, Chen Y (2012) The degradation influencing factors of Jiaozhou Bay wetland and ecological restoration suggestions (in Chinese). Marine Sciences 10:99-106 CNKI:SUN:HYKX.0.2012-10-014

Xie G, Zhang C, Zhang L, Chen W, Li S (2015) Improvement of ecosystem services valuation method based on value equivalent factor of unit area (in Chinese). J Natl Resources 30:1243-1254 CNKI:SUN:ZRZX.0.2015-08-001

Xie G, Zhang C, Zhen L, Zhang L (2017) Dynamic changes in the value of China's ecosystem services. Ecosystem Services 26:146154. https://doi.org/10.1016/j.ecoser.2017.06.010

Yin L, Dai E, Zheng D, Wang Y, Ma L, Tong M (2020) What drives the vegetation dynamics in the Hengduan Mountain region, Southwest China: climate change or human activity? Ecological Indicators 112:106013. https://doi.org/10.1016/j.ecolind.2019.106013
Yuan Y, Song D, Wu W, Liang S, Wang Y, Ren Z (2016) The impact of anthropogenic activities on marine environment in Jiaozhou Bay, Qingdao, China: a review and a case study. Regional Studies in Marine Science 8:287-296. https://doi.org/10.1016/j.rsma. 2016.01.004

Zhang X (2004) The impact of coastal wetland degradation on fishery production and biodiversity conservation in Jiaozhou Bay(in Chinese). Qilu Fish 9:34-36+5 CNKI: SUN:JOKE.0.2004-09-023

Zhao Y, Liu Q, Huang R, Pan H, Xu M (2020) Recent evolution of coastal tidal flats and the impacts of intensified human activities in the modern radial sand ridges, East China. International Journal of Environmental Research and Public Health 17(9):3191. https:// doi.org/10.3390/ijerph17093191

Publisher's Note Springer Nature remains neutral with regard to jurisdictional claims in published maps and institutional affiliations. 